\title{
Depression Treatment in Primary Care
}

\author{
W. David Robinson, PhD, Jenenne A. Geske, PhD, Layne A. Prest, PhD, and \\ Rachel Barnacle, MS
}

Background: Depression costs the United States \$40 billion annually. Primary care physicians play a key role in the identification and treatment of depression. This study focused on the treatment options recommended by physicians and whether physicians were following the recommended treatment guidelines.

Methods: We recorded treatment recommendations by examining charts for all patients with newly detected depression. The patients were from 44 family medicine practitioners and 23 general internal medicine practitioners in a Midwest university medical center setting.

Results: For both medical specialties combined, pharmacotherapy was the most widely used intervention (recommended for $\mathbf{5 2 \%}$ of patients), whereas psychotherapy alone was the least frequently used intervention (recommended for $\mathbf{4 \%}$ of patients). Family medicine practitioners recommended combination treatment (pharmacotherapy and psychotherapy) more frequently than did general internal medicine practitioners $(P=.022)$, and female physicians recommended combination treatment more frequently than did male physicians $(P=.010)$.

Conclusions: Pharmacotherapy was found to be the most widely used treatment despite current evidence-based recommendations. Barriers to effective treatment plan are discussed. The implications for mental health interventions, combination therapy, and cost offset are also discussed. Further research exploring the negotiation process during the patient-provider encounter would shed light on patient and physician factors influencing treatment decisions. (J Am Board Fam Pract 2005;18:79-86.)

Depression is the world's fourth most prevalent health problem, ${ }^{1}$ costing the United States $\$ 30$ to $\$ 50$ billion in lost productivity and direct medical costs each year. ${ }^{2,3}$ Persons who are depressed miss work because of illness at twice the rate of the general population. ${ }^{4}$ Health service costs are $50 \%$ to $100 \%$ greater for depressed patients than for comparable patients without depression. These increased costs are caused by higher medical utilization, not by specialty mental health care. ${ }^{5,6}$ Additional costs associated with depression include impaired concentration, failure to advance in educational and vocational endeavors, increased sub-

Submitted, revised, 15 October 2004.

From the Department of Family Medicine, University of Nebraska Medical Center, Omaha. Address correspondence to W. David Robinson, PhD, Department of Family Medicine, University of Nebraska Medical Center, $983075 \mathrm{Ne}-$ braska Medical Center, Omaha NE 68198-3075 (e-mail wdrobins@unmc.edu).

Preliminary data for this project were presented at the Annual Meeting of the Society for Teachers in Family Medicine; 2003 Sep 20-24; Atlanta, Georgia; and at the North American Primary Care Research Group; 2003 Oct 26; Banff, Alberta, Canada. stance abuse, impaired or lost relationships, and suicide. ${ }^{7,8}$

Primary care providers are the sole contacts for more than $50 \%$ of patients with mental illness and have thus been described as the de facto system of treatment for mental health. ${ }^{9-11}$ Reliable estimates suggest that symptoms consistent with depression are present in nearly $70 \%$ of patients who visit primary care providers. Approximately $35 \%$ of patients who are seen in primary care meet criteria for being diagnosed with some form of depression, with $10 \%$ of patients suffering from major depression. ${ }^{12-14}$ The prevalence of major depression is 2 to 3 times higher in primary care patients than in the overall population because depressed persons use health care more frequently. ${ }^{15,16}$ Therefore, because of the prevalence of depressed patients in primary care, physicians need to play an active role in effectively assessing, diagnosing, and treating depression.

To ensure effective treatment of this major health issue, the Agency for Health Care Policy and Research (AHCPR), the Veterans Health Administration/Department of Defense (VHA-DOD), 
and the American Psychiatric Association (APA) have published evidence-based recommendations for depression treatment. In summary, pharmacotherapy and psychotherapy (combination treatment) are recommended when treating moderate to severe depression. When the depression is mild to moderate and the patient is motivated to work on psychological/ interpersonal issues, psychotherapy is warranted. ${ }^{13,17,18}$ Schulberg et al (1999) concurred with the AHCPR guidelines and concluded that referral to a mental health specialist should be a part of depression treatment, especially when patients exhibit severe depressive symptoms (eg, suicide risk; comorbid medical, psychiatric, or substance use disorder; or failure to respond to appropriate treatment). ${ }^{1}$ However, in an overview of the outpatient treatment of depression between 1987 and 1997, Olfson et $\mathrm{al}^{19}$ found that, of those treated for depression in $1997,79.4 \%$ received pharmacotherapy, $60.2 \%$ received psychotherapy, and only $48.1 \%$ received combination therapy.

The purpose of this study was to determine whether local physicians were following the guidelines described above and to explore differences between certain groups of physicians. Therefore, the study sought to answer the following questions: "What are providers recommending as treatment for depression?" and "How do recommended treatments differ between family medicine and general internal medicine physicians and between male and female physicians?" It was hypothesized, in concurrence with past research, that pharmacotherapy would be the most frequently recommended treatment by all physicians. It was also hypothesized that family physicians would be more likely than general internal physicians to prescribe a wider variety of treatments, including psychotherapy treatment in combination with medication. Finally, based on research showing gender differences in the psychosocial skills of physicians, ${ }^{20,21}$ it was hypothesized that female physicians would prescribe alternatives to pharmacotherapy more often than male physicians.

\section{Methods}

\section{Procedures}

All family medicine $(\mathrm{n}=96)$ and general internal medicine physicians $(n=68)$ affiliated with a university medical center were initially identified as potential participants. A search of the centralized patient record system identified patients of these physicians who had been diagnosed with depression (based on ICD-9 codes) and who were seen between April 2000 and April 2002. During this study period, 78 of the 164 resident and faculty physicians (53 family medicine and 25 internal medicine) diagnosed patients with a new case of depression. All resident physicians were excluded from the study because of the possible influence of their attending physicians. The final sample of physicians consisted of 44 family medicine (FM) physicians and 23 internal medicine (IM) physicians (27 women and 40 men). The Institutional Review Board of the University of Nebraska Medical Center approved the study in June 2002.

To avoid any chart abstraction bias, we used all the charts of patients diagnosed with depression. A total of 2401 patients were identified. Because we focused only on newly diagnosed patients with uncomplicated depression, we excluded patients who had been treated for depression within the previous 6 months and those with comorbid anxiety and other related disorders.

The research assistant reviewed the charts of the remaining patients $(\mathrm{n}=580)$ and recorded demographic information on each patient (age, sex, race, and marital status). Patient identifying information was not recorded. The research assistant also used the dictated patient record to identify the patients' chief complaint, the presence or absence of symptoms related to depression (sleep, interest, guilt, energy, concentration, appetite, mood, psychomotor changes, suicide), any medications prescribed for mood disorders, the patients' insurance source, the ICD-9 diagnosis code used for the visit, and the recommended treatment. These treatments were grouped into 1 of 7 separate categories (pharmacotherapy, psychotherapy, pharmacotherapy + psychotherapy, counselor-recommended pharmacotherapy, watchful waiting, support group, or other). Because less than $5 \%$ of the patients were grouped into the "watchful waiting" and "support group" categories, these groups were combined with the "other" category for analysis.

\section{Statistical Analysis}

The research questions for this study concerned the physicians' treatment recommendations and how these recommendations might differ between FM and IM physicians and between female and 


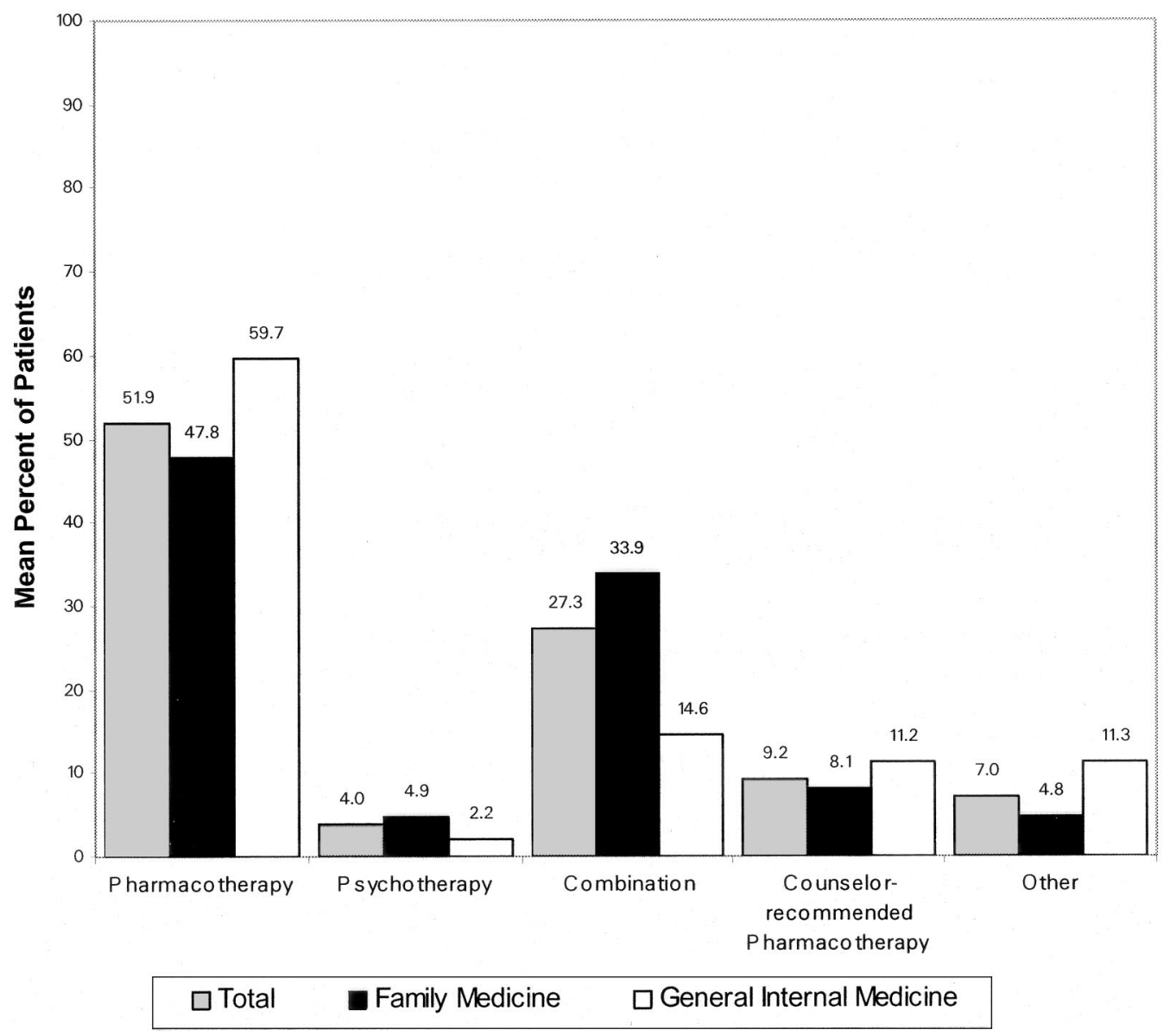

Figure 1. Mean percentage of patients who were recommended each treatment, by physician specialty.

male physicians. Thus, the primary unit of analysis was the physician rather than the patient. The outcome variable was the percentage of each physician's patients who were recommended each type of treatment.

Mixed method analyses of variance were used to determine whether the percentage of patients who were recommended for each of the treatment types interacted with medical specialty or gender of the physician.

\section{Results}

The charts of 580 patients from 44 FM physicians and $23 \mathrm{IM}$ physicians (27 women and 40 men) were reviewed. The number of eligible depression patients for each physician during the 2-year study period ranged from 1 to 54, with a median of 7 .

As hypothesized, the primary care physicians as a whole initiated pharmacological interventions more frequently than any other treatment. In particular, the physicians prescribed pharmacotherapy for an average of $52 \%$ of their newly diagnosed depressed patients, combination treatment (pharmacological and psychological) for an average of $27 \%$ of the patients, and psychotherapy alone for only $4 \%$ of the depression patients (Figure 1).

We found a significant interaction between recommended treatment and physician specialty $[\mathrm{F}(4,167)=3.5, P=.02] . \mathrm{FM}$ practitioners recommended combination treatment significantly more often than IM physicians. On the other hand, FM and IM physicians did not differ in their recommendation of psychotherapy alone, pharmacotherapy alone, counselor-recommended pharmacotherapy, and other treatments.

Consistent with the last hypothesis, female physicians suggested combination therapy significantly more than their male counterparts $(P=.01$; Figure $2)$, whereas male physicians suggested pharmacotherapy significantly more often $(P=.02)$. Despite these differences, the frequency with which male and female physicians recommended psychother- 


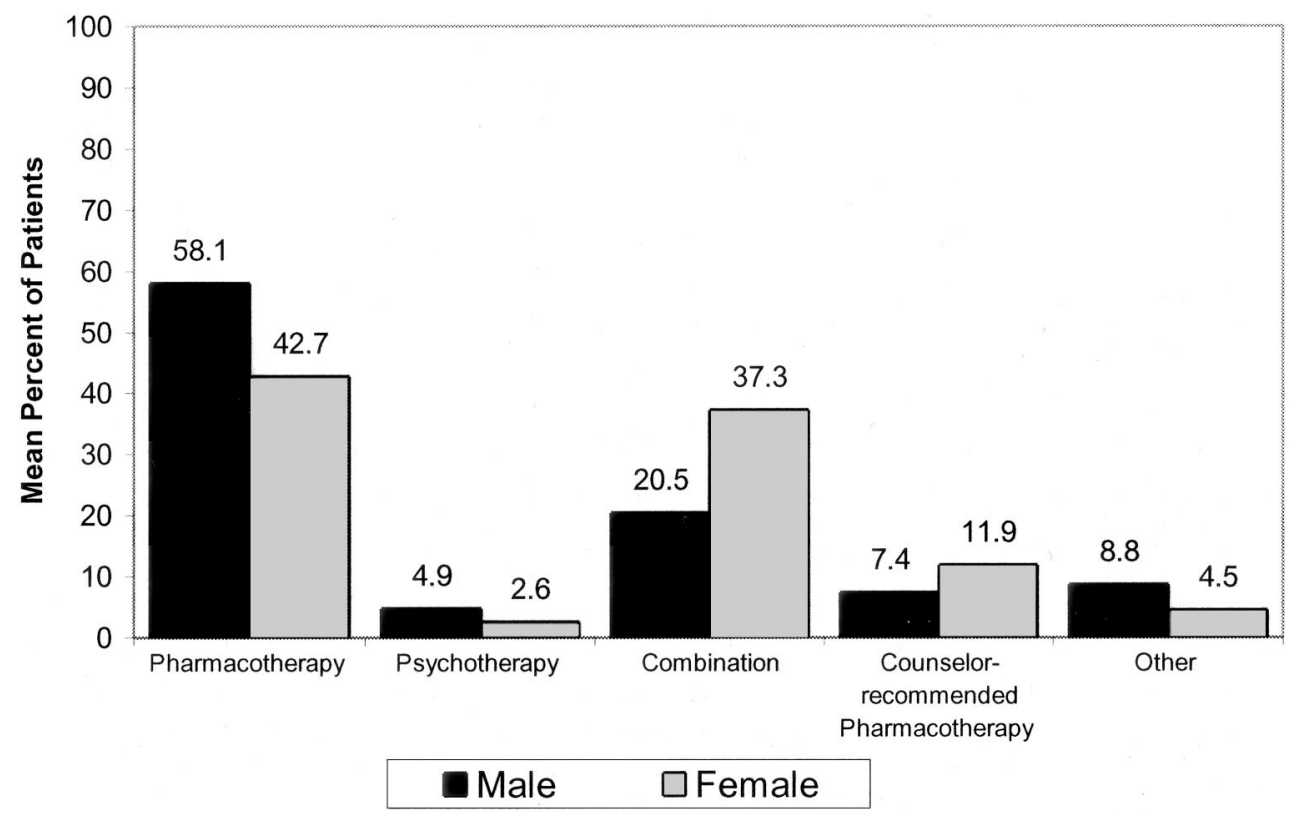

Figure 2. Mean percentage of patients who were recommended each treatment, by physician gender.

apy, counselor-recommended pharmacotherapy, or other treatments did not differ significantly.

Patient demographics were reviewed to determine whether the patient population differed between FM physicians and IM physicians. We found that the average age of patients of IM physicians was significantly higher (38.9 years, S.D. $=15.1$ ) than that of FM practitioners (35.7 years, S.D. = $13.2 ; \mathrm{F}=5.8, P=.02)$. In addition, $\mathrm{FM}$ physicians had a higher percentage of female patients $(78.6 \%)$ than did IM physicians $\left(60.4 \% ; \chi^{2}=19.5, P<\right.$ .001). IM physicians had a higher percentage of white patients $(94.2 \%)$ than FM physicians $(80.3 \%$; $\left.\chi^{2}=18.1, P<.001\right)$.

\section{Discussion \\ Hypotheses}

The results of this study were consistent with our hypotheses. Physicians prescribed pharmacotherapy more frequently than any other intervention. Female physicians were also more likely than male physicians to recommend psychotherapy to their depressed patients. In addition, FM and female physicians were more likely than IM and male physicians, respectively, to use combination therapy, with female physicians being the most likely to recommend such measures. Because of insufficient statistical power, it was difficult to isolate the interaction effects of specialty and gender on treat- ment decisions. Although no statistically significant interaction between physician gender and medical specialty was found, $46 \%$ of the FM physicians in this sample were women, whereas only $30 \%$ of the IM physicians were women.

\section{Theoretical and Practice Differences}

A possible explanation behind these results is that family physicians are encouraged to use a biopsychosocial model when working with patients. $^{22-24}$ On-site behavioral medicine faculty train FM physicians at this location in this model, which emphasizes assessing and treating the patient as a whole person, including recognizing the important role of cognition, affect, and the relationship context in the origin of and recovery from depression. The FM physicians in this setting also had mental health practitioners on site, so referrals to psychotherapy could be easily made, and the physician could discuss the patient's case with the therapist. This leads to the consideration of why other specialties are less likely than FM to hire psychotherapists to work within medical clinics. Further research on these trends is warranted.

\section{Gender Differences}

With regard to our investigation of gender differences, Hall, ${ }^{20}$ in a meta-analysis of provider characteristics, found that female providers spend more 
time with their patients, talk more about psychosocial topics, engage in more partnership building, and express more positive verbal and nonverbal behaviors than male doctors. Female physicians have shown significantly greater psychosocial orientation and patient-centeredness than male physicians. These differences could explain why more women choose to become FM than IM physicians. $^{21}$ This is important because current research and treatment recommendations indicate that psychotherapy is often a patient preference. ${ }^{25,26} \mathrm{~A}$ female doctor with partnership building skills may be more likely to ask for the patient's treatment preference (which is often psychotherapy), leading female physicians to refer their depressed patients to psychotherapy more frequently. The prevalence of female FM practitioners also suggests the likelihood of more combined prescriptions, given that women are both more likely to be FM physicians and to prescribe such treatments.

\section{Benefits of Psychotherapy as the Recommended Treatment}

There are many reasons that psychotherapy, alone or in combination with pharmacotherapy, should be the recommended treatment. Not only is psychotherapy often the patient's preference, but therapy approaches, specifically cognitive, behavioral, or interpersonal models, have also been shown to be at least as effective as medication in treatment of mild to moderate depression. ${ }^{1,27}$ Ward et al (2000) found that psychological therapy reduced depression more quickly than traditional general practitioner care. ${ }^{28}$ Psychotherapy combined with medical therapy is an option for patients who do not respond to either alone. ${ }^{14,19,29}$ Researchers have found that patients with a severe depressive disorder who are treated with a combination of psychotherapy and pharmacotherapy had an $85 \%$ remission rate as opposed to $55 \%$ for medication, and $52 \%$ in response to psychotherapy. ${ }^{25}$ This finding indicates that combination therapy is the most effective treatment strategy available and is indicated for severely depressed patients. Despite the research findings, the current study confirms that pharmacotherapy continues to be the primary treatment modality among primary care physicians. ${ }^{19,30}$

The guidelines cited in the introduction recommend psychotherapy for all levels of depression, with the addition of pharmacotherapy for patients with moderate or severe depression. In addition, combination therapy (ie, psychotherapy and pharmacotherapy) has also been recommended for use when patients present with a more complex major depressive disorder. ${ }^{14}$ For example, a fairly common yet underdiagnosed mood disorder frequently manifesting with symptoms of depression is bipolar disorder. ${ }^{31}$ Although combination treatment is recommended for both depression and bipolar disorder, the suggested pharmacotherapy regimens for these 2 mood disorders are different. Therefore, a correct diagnosis is critical. Barriers to a correct diagnosis will be discussed in more detail below.

\section{Reduced Need for Health Care Services: Cost Offset}

Another advantage to the prescription of psychotherapy or combination therapy is that persons who receive individual, couple, or family therapy have been found to require health care services less often after their therapy was completed. For example, Law et $\mathrm{al}^{32}$ found that individuals receiving marital and family therapy significantly decreased their use of medical services by $53 \% 6$ months after termination of therapy. Similar results were found in those persons receiving individual therapy; their health care utilization significantly decreased by $48 \%$. Thus, prescribing psychotherapy or combination therapy to depressed persons can significantly lower the health service costs associated with these patients.

\section{Barriers to Effective Treatment}

The results from this study led the researchers to question why there is such a discrepancy between research on effective depression treatment and patient preferences on the one hand and actual treatment decisions on the other. Many barriers to effective depression treatment have been previously identified, including underdiagnosis of depression. The US Preventive Services Task Force ${ }^{33}$ reported that depression is undetected in up to $50 \%$ of all cases in primary care.

\section{Adherence}

Once patients are screened, diagnosed, and prescribed treatment, their adherence to the treatment plan becomes a potential barrier to effectively addressing the depression. Twenty-five to $30 \%$ of primary care patients treated with antidepressant medication discontinue treatment within 1 month, 
and $40 \%$ to $50 \%$ stop treatment within 3 months. ${ }^{34,35}$

\section{Finances and Insurance}

Finances can contribute to lack of patient adherence to treatment. Although there seems to be no difference in cost among general practitioner care, cognitive-behavioral therapy, and nondirective counseling, ${ }^{36,37}$ whether or not the patient possesses insurance and the type of insurance coverage seems to influence which treatment is prescribed for a depressed patient. For example, patients who had private insurance were more likely than those who did not to receive pharmacotherapy for the treatment of their depression. ${ }^{38}$ For this reason, patients were then less likely to receive combination therapy-the most effective treatment modality for depression.

Furthermore, patients who have little or no mental health third party coverage will often not be able to follow through on the referral for mental health services. Thus, to spare their patients financial hardship (which could intensify rather than treat the depression), physicians will purposely not diagnose patients as depressed, even when they meet the criteria for a major depressive episode. They will treat the physical symptoms (eg, lack of sleep, decreased appetite, fatigue, etc), but not the psychological ones (eg, sadness, hopelessness, guilt, etc). ${ }^{39}$

\section{Physician-Patient Communication}

In addition to financial concerns, another barrier may be ineffective physician-patient communication. Past evidence suggests that effective physician-patient communication leads to improved depression identification, treatment, and patient satisfaction. ${ }^{40-46}$ Patients state that physicians do not encourage them to ask questions, ask their opinions about the ailment or treatment, or give advice on lifestyle changes that could possibly affect patients' health. In general, patients are satisfied with the competency of medical care, but feel that communication with their physician is lacking. ${ }^{47}$ In addition, Nutting et $\mathrm{al}^{48}$ suggested that poor physician-patient interaction may reduce the likelihood that primary care physicians will use treatment strategies other than medication.

Improving physician-patient communication may not only lead to improved identification and treatment of depression but also aid in the accurate diagnosis and subsequent treatment of more complex mood disorders that may initially appear as depression, such as bipolar disorder. ${ }^{49}$ Studies suggest that $30 \%$ to $40 \%$ of patients in psychiatric and primary care settings who have been diagnosed with major depression are inaccurately diagnosed and meet the criteria for bipolar II disorder. ${ }^{31,50}$

\section{Concerns with Antidepressants and Bipolar Patients}

According to the National Institute of Mental Health (NIMH), the recommended treatment for bipolar disorder is a combination treatment (ie, psychotherapy and pharmacotherapy). ${ }^{51}$ In fact, there is evidence that prescribing standard antidepressants to patients with bipolar disorder may induce mania or worsen the disorder over the long term. ${ }^{52}$ If antidepressant medications without psychotherapy are used for the treatment of bi-polar disorder, guidelines recommend that a "mood stabilizer" be included as part of the treatment. ${ }^{51,52}$ Ineffective physician-patient communication may contribute to the inaccurate diagnoses and subsequently the potentially damaging treatment recommendation of antidepressant medications alone. It is clear that a better understanding of the physician-patient communication process is needed. Improving the physician/patient communication process is vital in improving the care provided to depressed patients.

\section{Study Limitations}

One limitation of this study is the small sample size. This study used a convenience sample. Consequently the researchers did not control for gender, age, ethnic group, and other demographic and social characteristics. In addition, the sample is representative of only the Midwest urban population, so the results cannot be widely generalized.

\section{The Need for Further Research}

The results of this pilot study point to the need for further research. To verify the current treatment strategies indicated by these results, a larger, nationally representative sample of physicians would be an important next step. More complex mood disorders, such as bipolar and anxiety disorders, should also be included in future studies. In addition, a study including IM physicians who also have psychotherapists available on-site for referral would ensure clearer results regarding differences 
between IM and FM physicians' treatment recommendations.

Although the current literature describes physician treatment decisions, patient preferences, and treatment outcomes, further research efforts need to focus on what occurs during the patient-physician negotiation of treatment that so often results in drug prescriptions rather than other treatments. A detailed examination of the initial encounter between the physician and a depressed patient can provide researchers the knowledge necessary to design interventions that will enhance the physicianpatient interaction and result in decisions that will improve the treatment of this major health problem.

We gratefully acknowledge the assistance of Kimberly A. Borke in collecting data for this study.

\section{References}

1. Schulberg HC, Katon WJ, Simon GE, Rush AJ. Best clinical practice: Guidelines for managing major depression in primary medical care. J Clin Psychiatry 1999;60 Suppl 7:19-26.

2. Greenberg PE, Finkelstein SN, Berndt ER. Calculating the workshop cost of chronic disease. Bus Health 1995;13:27-28, 30.

3. Rice DP, Miller LS. Health, economics, and cost implications of anxiety and other mental disorders in the United States. Br J Psychiatry Suppl 1998;34: 4-9.

4. Von Korff M, Katon WJ, Unutzer J, Wells KB, Wagner EH. Improving depression care: barriers, solutions, and research needs. J Family Pract 2001; 50:E1.

5. Henk H, Katzelnick DJ, Kobak KA, Greist JH, Jefferson JW. Medical costs attribution to depression among patients with a history of high medical expenses in a health maintenance organization. Arch Gen Psychiat 1996;53:899-906.

6. Simon GE, VonKorff M. Recognition, management, and outcomes of depression in primary care. Arch Family Med 1995;4:99-105.

7. Pincus HA, Pettit AR. The societal costs of chronic major depression. J Clin Psychiatry 2001;62 Suppl 6:5-9.

8. Greden JF. The burden of recurrent depression: causes, consequences, and future prospects. J Clin Psychiatry 2001;62 Suppl 22:5-9.

9. Montano DE, Manders DB, Phillips WR. Family physician beliefs about cancer screening: development of a survey instrument. J Family Pract 1990; 30:313-9.

10. Regier DA, Goldberg ID, Taube CA. The de facto
US mental health services system: a public health perspective. Arch Gen Psychiatry 1978;35:685-93.

11. Callahan EJ, Bertakis KD, Azari R, Robbins J, Helms LJ, Miller J. The influence of depression on physician-patient interaction in primary care. Fam Med 1996;28:346-51.

12. Montano CB, Montano MB. A new paradigm for treating depression in the primary care setting [monograph on the Internet]. Medscape Medical News; 2002 [cited 2004 Oct 10]. Available from: www.medscape.com/viewprogram/2022_pnt.

13. AHCPR Depression Guideline Panel. Clinical Practice Guideline Number 5. Depression in primary care. Volume 2: treatment of major depression. AHCPR publication no. 93-0550. Rockville (MD): Agency for Health Care Policy and Research, Public Health Services, US Department of Health and Human Services; 1993.

14. Thase ME. When are psychotherapy and pharmacotherapy combinations the treatment of choice for major depressive disorder? Psychiatr Q 1999;70: 333-46.

15. Regier DA, Narrow WE, Rae DS, Manderscheid RW, Locke BZ, Goodwin FK. The de facto U.S. mental and addictive disorders service system. Epidemiologic catchment area prospective 1-year prevalence rates of disorders and services. Arch Gen Psychiatry 1993;50:85-94.

16. Coyne JC, Fechner-Bates S, Schwenk TL. Prevalence, nature, and comorbidity of depressive disorders in primary care. Gen Hosp Psychiatry 1994;16: 267-76.

17. American Psychiatric Association Workgroup on Major Depressive Disorder. Practice guideline for the treatment of patients with major depressive disorder. Washington DC: American Psychiatric Association; 2000. Available at: http://www.psych.org/ psych_pract/treatg/pg/Depression2e.book.cfm

18. The Management of Major Depressive Disorder Working Group. Clinical practice guideline for the management of major depressive disorder in adults, version 2.0. Washington DC: Veterans Health Administration/Department of Defense; 2000.

19. Olfson M, Marcus SC, Druss BG, Elinson L, Tanielian T, Pincus HA. National trends in the outpatient treatment of depression. JAMA 2002;287:203-9.

20. Hall JA, Roter DL. Do patients talk differently to male and female physicians? A meta-analytic review. Patient Educ Couns 2002;48:217-24.

21. Jenkins V, Fallowfield L. Can communication skills training alter physicians' beliefs and behavior in clinics? J Clin Oncol 2002;20:765-9.

22. Reyes-Ortiz C. Internal medicine and family medicine [letter]. Ann Intern Med 1996;125:525-6.

23. McDaniel SH, Hepworth J, Doherty WJ. Medical family therapy: a biosocial approach to families with health problems. New York: BasicBooks/HarperCollins Publishers; 1992. 
24. Marvel MK, Major G, Jones K, Pfaffly C. Dialogues in the exam room: medical interviewing by resident family physicians. Fam Med 2000;32:628-32.

25. Keller MB, McCullough JP, Klein DN, et al. A comparison of nefazodone, the cognitive behavioralanalysis system of psychotherapy, and their combination for the treatment of chronic depression. N Engl J Med 2000;342:1462-70. Erratum in: N Engl J Med 2001;345:232.

26. Bedi N, Chilvers C, Churchill R, et al. Assessing effectiveness of treatment of depression in primary care. Partially randomised preference trial. Br J Psychiatry 2000;177:312-8.

27. Goldapple K, Segal Z, Garson C, et al. Modulation of cortical-limbic pathways in major depression: treatment-specific effects of cognitive behavior therapy. Arch Gen Psychiatry 2004;61:34-41.

28. Ward E, King M, Lloyd M, et al. Randomised controlled trial of non-directive counselling, cognitivebehaviour therapy, and usual general practitioner care for patients with depression. I: clinical effectiveness. BMJ 2000;321:1383-8.

29. Thase ME. Integrating psychotherapy and pharmacotherapy for treatment of major depressive disorder. Current status and future considerations. J Psychother Pract Res 1997;6:300-6.

30. Schulberg HC, Katon WJ, Simon GE, Rush AJ. Treating major depression in primary care practice. Arch Gen Psychiatry 1998;55:1121-7.

31. Manning JS, Haykal RF, Akiskal HS. The role of bipolarity in depression in the family practice setting. Psychiatr Clin North Am 1999;22:689-703.

32. Law DD, Crane DR, Berge JM. The influence of individual, marital, and family therapy on high utilitzers of health care. J Marital Fam Ther 2003;29: 353-63.

33. US Preventive Services Task Force now finds sufficient evidence to recommend screening adults for depression. Press release. Rockville (MD): Agency for Healthcare Research and Quality; 2002 [cited 2002 Nov 12]. Available from: http://www.ahrq.gov/ news/press/pr2002/deprespr.htm

34. Fairman KA, Drevets WC, Kreisman JJ, Teitelbaum F. Course of antidepressant treatment drug type, and prescriber's specialty. Psychiatr Serv 1998;49: 1180-6.

35. Simon GE, Von Korff M, Ludman EJ, et al. Costeffectiveness of a program to prevent depression relapse in primary care. Med Care 2002;40:941-50.

36. Bower P, Rowland N, Mellor C, Heywood P, Godfrey C, Hardy R. Effectiveness and cost effectiveness of counselling in primary care. Cochrane Database Syst Rev 2002;(1):CD001025.

37. Bower P, Byford S, Sibbald B, et al. Randomised controlled trial of non-directive counselling, cognitive-behaviour therapy, and usual general practitioner care for patients with depression. II: cost effectiveness. BMJ 2000;321:1389-92.
38. Sclar DA, Robinson LM, Skaer TL, Galin RS. Trends in the prescribing of antidepressant pharmacotherapy: office-based visits, 1990-1995. Clin Ther 1998;20:871-84.

39. Goldman LS, Nielsen NH, Champion HC. Awareness, diagnosis, and treatment of depression. J Gen Intern Med 1999;14:569-80.

40. Bull SA, Hu XH, Hunkeler EM, et al. Discontinuation of use and switching of antidepressants: influence of patient-physician communication. JAMA 2002;288:1403-9.

41. Bultman DC, Svarstad BL. Effects of physician communication style on client medication beliefs and adherence with antidepressant treatment. Patient Educ Couns 2000;40:173-85.

42. Carney PA, Dietrich AJ, Eliassen MS, Owen M, Badger LW. Recognizing and managing depression in primary care: a standardized patient study. J Fam Pract 1999;48:965-72.

43. Cooper-Patrick L, Powe NR, Jenckes MW, Gonzales JJ, Levine DM, Ford DE. Identification of patient attitudes and preferences regarding treatment of depression. J Gen Intern Med 1997;12: 431-8.

44. Demyttenaere K. Compliance during treatment with antidepressants. J Affect Disord 1997;43:27-39.

45. Deveugele M, Derese A, Maeseneer JD. Is GPpatient communication related to their perceptions of illness severity, coping and social support? Soc Sci Med 2002;55:1245-53.

46. Kurtz SM. Doctor-patient communication: principles and practices. Can J Neurol Sci 2002;29 Suppl 2:S23-9.

47. How is your doctor treating you? Consumer Reports 1995;60:81-8.

48. Nutting PA, Rost KM, Dickinson M, et al. Barriers to initiating depression treatment in primary care practice. J Gen Intern Med 2002;17:103-11.

49. Benazzi F. Frequency of bipolar spectrum in 111 private practice depression outpatients. Eur Arch Psychiatry Clin Neurosci 2003;253:203-8.

50. Hantouche EG, Akiskal HS, Lancrenon S, et al. Systemic clinical methodology for validating bipolar-II disorder: data in mid-stream from a French national multi-site study (EPIDEP). J Affect Disord 1998;50:163-73.

51. National Institute of Mental Health. Bipolar disorder [monograph on the Internet]. Rockville (MD): National Institute of Mental Health, National Institutes of Health, Public Health Service, Department of Health and Human Services; 2001. [cited 2004 Sep 15[. Available from: http://www.nimh.nih.gov/ publicat/bipolar.cfm.

52. Sachs GS, Koslow CL, Ghaemi SN. The treatment of bipolar depression. Bipolar Disord 2000;2:25660. 